\title{
CONTRADIÇÕES DA EDUCAÇÃO DE JOVENS E ADULTOS EM TEMPOS DE EDUCAÇÃO REMOTA
}

\author{
CONTRADICTIONS OF YOUTH AND ADULT EDUCATION \\ IN TIMES OF REMOTE EDUCATION
}
CONTRADICCIONES DE LA EDUCACIÓN DE JÓVENES Y ADULTOS
EN TIEMPOS DE EDUCACIÓN A DISTANCIA

Jaqueline Luzia da Silva'; Carlos Soares Barbosa²

RESUMO

O objetivo deste artigo é analisar as potencialidades e limites das práticas pedagógicas mediadas por tecnologias digitais, no atual contexto em que o mundo convive com a pandemia da Covid-19, que impediu, além de outras atividades cotidianas, que as escolas dessem continuidade ao ano letivo de 2020 e iniciassem o ano letivo de 2021. O presente estudo centra-se na modalidade da Educação de Jovens e Adultos (EJA), nos níveis Fundamental e Médio, sob a hipótese de que os educandos da modalidade são os que possuem maiores dificuldades de adaptação às novas práticas de ensino e de aprendizagem com interface tecnológica, devido à pouca habilidade da maioria dos estudantes no uso de equipamentos eletrônicos e à ausência do acesso à internet. Trata-se de pesquisa de abordagem quali-quantitativa, que metodologicamente fez uso de questionário, respondido por 79 professores, por meio de formulário digital. As principais conclusões do estudo apontam a baixa adesão dos estudantes da modalidade às plataformas digitais, às atividades remotas e a necessidade de as políticas públicas e a formação docente investirem na educação mediada pela tecnologia como um recurso a mais, no processo de ensino e de aprendizagem e na garantia do direito de todos à educação. Sinaliza, ainda, como professores e estudantes estão vivenciando este contexto pandêmico e as expectativas docentes em relação à EJA no período pós-pandemia.

PALAVRAS-CHAVE: Educação de Jovens e Adultos (EJA). Direito à educação. Desafios educacionais.

\section{ABSTRACT}

The aim of this article is to analyze the potentialities and limits of pedagogic practices mediated by digital technologies, in current context in which the world coexists with Covid-19, that prevented, beyond other daily activities, that the schools have continued the school year of 2020 and have begun the school year of 2021. The present study is centered in the Youth and Adult Education (YAE), in Elementary and High levels, under the hypotheses that the students of the YAE are who have higher difficulties of adaptation to the newest teaching and learning practices with technologic interface, due the low ability of the most students in the usage of electronic equipment and absence of access to internet. This research has a qualitative-quantitative approach, which methodologically used questionnaire, answered by 79 teachers, through digital formulary. The main conclusions of the study point to low adhesion of the YAE students to digital platforms and remote activities, and the necessity of the public politics and teacher training to invest in education mediated by technology as an extra resource in teaching and learning process and in the warranty of the right to education for all. It also signals how teachers and students are experiencing this pandemic context and the teachers expectatives about YAE in after-pandemic period.

\footnotetext{
${ }^{1}$ Doutora em Educação - Pontifícia Universidade Católica do Rio de Janeiro (PUC-Rio). Rio de Janeiro, RJ. Brasil. Professora Adjunta da Faculdade de Educação - Universidade do Estado do Rio de Janeiro (UERJ). Rio de Janeiro, RJ - Brasil. E-mail: jaquelineldasilva@gmail.com

${ }^{2}$ Doutor em Políticas Públicas e Formação Humana - Universidade do Estado do Rio de Janeiro (UERJ). Rio de Janeiro, RJ - Brasil. Professor Adjunto da Faculdade de Educação - Universidade do Estado do Rio de Janeiro (UERJ). Rio de Janeiro, RJ - Brasil. E-mail: profcarlossoares@gmail.com
}

Submetido em: 27/05/2021 - Aceito em: 19/10/2021

(C) ETD-Educação Temática Digital $\quad$ Campinas, SP $\quad$ v.24 $\quad$ n.1 $\quad$ p. 14-31 jan./abr. 2022


KEYWORDS: Youth and Adults Education (YAE). Right to Education. Educational challenges.

\section{RESUMEN}

El objetivo de este artículo es analizar las potencialidades y los límites de las prácticas pedagógicas mediadas por las tecnologías digitales, en el contexto actual en el que el mundo vive con la pandemia del Covid-19, que impidió, además de otras actividades cotidianas, que las escuelas continuaran el año escolar 2020 e iniciaran el año escolar 2021. Este estudio se centra en la modalidad de Educación de Jóvenes y Adultos (EJA), en los niveles de Primaria y Secundaria, bajo la hipótesis de que los alumnos de esta modalidad son los que tienen mayores dificultades para adaptarse a las nuevas prácticas de enseñanza y aprendizaje con interfaz tecnológica, dada la baja habilidad de la mayoría de los alumnos en el uso de equipos electrónicos y la ausencia de acceso a internet. Se trata de una investigación de enfoque cuali-cuantitativo, que metodológicamente hizo uso de un cuestionario, contestado por 79 profesores, mediante formulario digital. Las principales conclusiones del estudio apuntan a la baja adhesión de los alumnos de la modalidad a las plataformas digitales y a las actividades a distancia y a la necesidad de que las políticas públicas y la formación de los profesores inviertan en la educación mediada por la tecnología como un recurso más en el proceso de enseñanza y aprendizaje y en la garantía del derecho de todos a la educación. También señala cómo viven los profesores y los alumnos este contexto pandémico y las expectativas de los profesores en relación con la EJA en el periodo post-pandémico.

PALAVRAS-CLAVE: Educación de Jóvenes y Adultos (EJA). Derecho a la educación. Desafíos educativos.

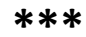

\section{INTRODUÇÃO}

O objetivo deste artigo é analisar as potencialidades e limites das práticas pedagógicas mediadas por tecnologias digitais, no atual contexto em que o mundo convive com a pandemia da Covid-19, que impediu, além de outras atividades cotidianas, que as escolas dessem continuidade ao ano letivo de 2020 e iniciassem o ano letivo de 2021. Desde então, no Brasil, as atividades pedagógicas presenciais foram substituídas por educação mediada por tecnologia. Ensino híbrido, ensino remoto, sala de aula invertida e metodologias ativas foram alguns dos vocábulos - até então pouco conhecidos - que se impuseram no cotidiano dos professores, mas que não podem ser tratados como educação à distância (EaD), uma vez que esta possui materiais apropriados e elaborados com linguagem e conteúdo específicos, formação de docentes e de mediadores para atuarem na modalidade, além de acompanhamento, avaliações e plataformas digitais adequadas. Professores foram instados a acompanhar suas turmas utilizando-se da internet e suas ferramentas, a fim de dar continuidade ao ano letivo e a convivência com os alunos. Nesses termos, uma nova rotina se configurou e tem exigido novas habilidades dos professores diante das tecnologias digitais.

O presente estudo centra-se na modalidade da Educação de Jovens e Adultos (EJA), nos níveis Fundamental e Médio, da rede estadual de educação do Rio de Janeiro e de oito redes municipais deste estado, sob a hipótese inicial de que os educandos da modalidade são os que possuem maiores dificuldades de adaptação às novas práticas de ensinoaprendizagem com interface tecnológica, dada à pouca habilidade da maioria dos estudantes, já que muitos não dispõem de equipamentos como notebook, tablet ou desktop, mas apenas aparelho celular com internet limitada à base de pacote de dados. Realidade não muito

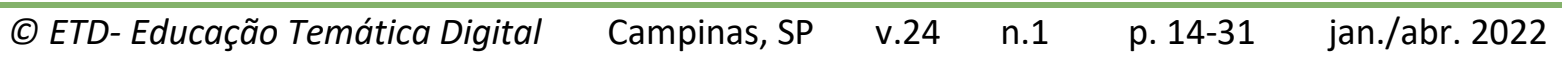


diferente dos professores - produto da ausência de políticas públicas de inclusão e acesso às tecnologias digitais. Embora já se aponte, desde o final do século XX, a necessidade de as escolas brasileiras e as redes de ensino investirem nas tecnologias digitais como aliadas no processo de ensino e de aprendizagem, pouca atenção foi conferida à democratização digital em termos de investimentos, planejamentos e formação de professores para utilização das ferramentas e recursos que hoje se tornam necessários. O resultado desse processo é a fragilidade dos sistemas públicos de ensino na formação dos sujeitos demandados na fase do desenvolvimento digital-molecular.

Se, historicamente, a modalidade EJA já tinha um lugar marginal nas políticas públicas educacionais, nos últimos anos ela vem perdendo progressivo espaço na agenda governamental, principalmente desde o golpe jurídico, midiático e parlamentar de $2016^{3}$ e sua total invisibilidade nas políticas do atual governo Bolsonaro. Como destacam Barbosa e Silva (2020), a extinção dos programas federais e de órgãos do Ministério da Educação responsáveis em articular/estimular políticas aos estados e municípios, a redução significativa do orçamento destinado à modalidade e a progressiva redução das matrículas não têm suscitado mobilizações em defesa da modalidade, tanto por parte dos professores quanto dos principais prejudicados: jovens, adultos e idosos interditados historicamente do direito à educação.

Recentemente, verifica-se na EJA um movimento caracterizado por fechamento de turmas e escolas, além de uma intensa queda do número de matrículas. "[...] Enquanto em 2010, os estudantes da EJA abarcavam 8,3\% do total de matriculados na Educação Básica no Brasil, em 2019 somaram apenas 6,7\%, representando 1.051 .919 matrículas a menos" (SANCEVERINO et al., 2020, p. 2). Paradoxalmente, com relação ao investimento, "a EJA sofreu a maior retração do financiamento educacional e das ações executadas pelo MEC entre 2016 e 2019, pois nesse período, o orçamento pago para a EJA declinou de 485,4 para 21,2 milhões de reais" (SANCEVERINO et al., 2020, p. 3).

Em específico ao Rio de Janeiro, Serra et al. (2018) destacam que:

Dos 92 municípios do Rio de Janeiro, 65 apresentavam uma taxa de atendimento inferior a $15 \%$ e oito não possuíam nenhuma matrícula na EJA/EM. Nos 19 restantes, essa taxa não passa de $30 \%$. No geral, os dados do Censo Escolar levantados pelo INEP junto às secretarias de educação demonstram que essa diminuição das matrículas ocorreu em pelo menos 87 municípios do Rio de Janeiro, quando comparados os anos de 2010 e 2014. [...] Comparando a evolução das matrículas, havia 263.978 matrículas no ensino fundamental da EJA, em 2010, sendo reduzidas a 133.279 em 2014. Quanto ao ensino médio, as matrículas caíram de 163.311, em

\footnotetext{
${ }^{3}$ Fazemos uso do termo golpe para referenciar o impeachment sofrido pela presidente Dilma Rousseff e que fora admitido publicamente, mais tarde, por Michel Temer, em um programa de entrevistas na TV. (Fonte: https://www.redebrasilatual.com.br/politica/2019/09/golpe-temer-ponte-para-bolsonaro/ )
}

(C) ETD-Educação Temática Digital Campinas, SP $\quad$ v.24 $\quad$ n.1 $\quad$ p. 14-31 jan./abr. 2022


2010, para 100.748 em 2014. Isso significa mais de 130 mil alunos a menos no ensino fundamental e mais de 62 mil alunos a menos no ensino médio em quatro anos. (SERRA et al., 2018, p. 28)

No contexto da pandemia, esses desafios se acirram ainda mais. Com a intenção de investigar esta realidade, as questões que norteiam o nosso estudo são: que estratégias têm sido utilizadas pelos docentes com o intuito de garantir o direito à educação de jovens, adultos e idosos no atual momento de pandemia no Brasil? Considerando que os educandos da EJA são majoritariamente trabalhadores de baixo poder aquisitivo, muitos dos quais não possuem em suas residências espaços apropriados para a rotina do estudo, e tendo em vista a perda significativa de renda familiar devido à situação de desemprego provocada pela necessidade de distanciamento social em decorrência da pandemia da Covid-19, como os professores e estudantes da modalidade estão respondendo as exigências do ensino remoto? Quais as estratégias criadas pelos docentes para contornar as dificuldades dos educandos ao acesso aos recursos tecnológicos e às barreiras de outras naturezas, como a cultura do ensino presencial? Quais as aprendizagens esperadas dos sujeitos e como têm sido as propostas de avaliação destas aprendizagens? Quais as condições materiais e emocionais de professores e estudantes para elaboração das atividades e realização das propostas pedagógicas?

Com o intuito de responder tais questões, propomos uma pesquisa de abordagem quali-quantitativa, denominada "EJA em tempos de educação remota", que metodologicamente fez uso de questionário com questões abertas e fechadas, enviado para aproximadamente 150 professores, por meio de formulário digital, entre os meses de outubro e dezembro de 2020 - cerca de oito meses após o fechamento das escolas devido à orientação de distanciamento social. Do total de questionários enviados, obteve-se 79 respostas de professores, dos quais $94,9 \%$ atuam na rede pública e 5,1\% na rede privada. Todos assinaram o Termo de Consentimento Livre e Esclarecido e foi respeitado o seu anonimato.

No período da pesquisa, além da implantação das atividades remotas, questões referentes ao controle da prática docente, à segurança alimentar dos estudantes, às políticas e práticas curriculares, ao retorno das aulas presenciais, entre outras, passaram a fazer parte de debates entre profissionais da educação, gestores da educação pública e a sociedade como um todo (NICODEMOS e SERRA, 2020, p.872). Desse modo, a importância de refletir sobre os desafios vivenciados pela modalidade no ensino remoto emergencial se justifica no sentido de se buscar, desde já, as condições mais adequadas para a modalidade no período póspandemia, questionando os sentidos que são/serão dados aos avanços tecnológicos em um país onde impera a lógica neoliberal e a desigualdade social. Por essa perspectiva, este trabalho objetiva contribuir com as reflexões sobre as novas formas de reprodução da dualidade estrutural da educação brasileira, que impedem que parte significativa da população tenha efetivamente garantido um dos direitos humanos fundamentais.

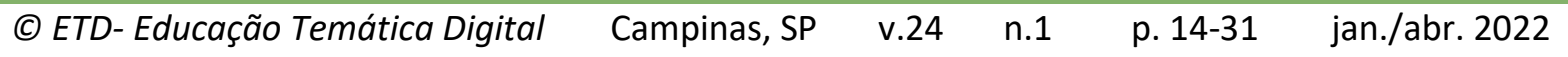




\section{SOBRE A PESQUISA REALIZADA - PERFIL DOS PROFESSORES PARTICIPANTES}

O questionário aplicado e enviado aos professores, composto por 30 questões, se constituiu de cinco partes, a saber: (i) identificação pessoal (idade, identidade de gênero e identidade étnico-racial); (ii) formação acadêmica; (iii) atuação profissional (nível, sistema, administração e município em que leciona); (iv) tempo em atividade profissional e carga horária semanal de trabalho (no ensino regular, na EJA e na escola) e (v) questões sobre o ensino remoto na EJA no contexto da pandemia.

Quanto ao perfil dos 79 participantes da pesquisa, 57 são mulheres e 22 homens, cuja maioria encontra-se na faixa etária de 41 a 60 anos (54 pessoas). Todos possuem ensino superior completo e mais da metade (46 professores, o correspondente a $58,2 \%$ ) possui curso de especialização em nível de pós-graduação lato sensu. Uma pequena maioria atua no primeiro segmento do Ensino Fundamental (38\%) e cerca de um terço atua no segundo segmento $(29,1 \%)$ e no Ensino Médio (32,9\%). Dos 75 professores que trabalham no sistema público de ensino, 47 atuam nas redes municipais.

Os municípios do Estado do Rio de Janeiro em que os participantes trabalham, tanto na rede municipal quanto estadual de ensino, são: Rio de Janeiro (62); Nova Iguaçu (6); Mesquita (5); Niterói (2); Duque de Caxias (1); Engenheiro Pedreira (1); Itaboraí (1) e São Gonçalo (1). Entre os pesquisados, 35 professores (44\%) atuam há mais de vinte anos no ensino regular e 29 (36\%) atuam entre cinco e dez anos na modalidade EJA. Quanto à carga horária de trabalho, 46 docentes (58\%) trabalham até 30 horas por semana.

\section{POTENCIALIDADES E LIMITES DAS PRÁTICAS PEDAGÓGICAS NA EJA MEDIADAS POR TECNOLOGIAS DIGITAIS, NO ATUAL CONTEXTO DA PANDEMIA DA COVID-19}

Desde a promulgação da Lei de Diretrizes e Bases da Educação Nacional (LDB) n. 9394, de 1996, a EJA foi legitimada como modalidade de ensino dentro dos níveis Fundamental e Médio. A exigência da EJA nos termos da Lei garantiu a ela suas especificidades próprias, apontadas no Parecer CNE/CEB n. 11/2000. Tais especificidades estabelecem os fundamentos e funções da EJA, suas bases legais, bases histórico-sociais, formação docente específica e Diretrizes Curriculares Nacionais para a modalidade (BRASIL, 2000).

No ano de 2010, a resolução n. 3 do Ministério da Educação instituiu as Diretrizes Operacionais para a EJA, corroborando o que previa a LDB em termos da idade mínima para o ingresso na EJA (15 anos no Ensino Fundamental e 18 anos no Ensino Médio), além de estabelecer a carga horária mínima dos cursos e legitimar a EaD a partir do segundo segmento do Ensino Fundamental (BRASIL, 2010). Posteriormente, o Decreto n. 9.057/2017 instituiu

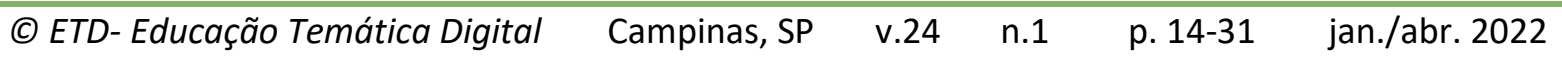


que compete às autoridades dos sistemas de ensino autorizar os cursos e o funcionamento de instituições de EaD também na EJA (BRASIL, 2017). De certo modo, essas normativas vão ao encontro da proposta anunciada pelo Governo Michel Temer (2016-2018) de oferecer 80\% da carga horária total da educação para as pessoas jovens, adultas e idosas por meio da EaD, demonstrando estar em curso o projeto de desescolarização da EJA gerado a partir de o golpe de 2016.

No Rio de Janeiro, indicativos desse processo se desvelam no fechamento de escolas de EJA e, consequentemente, na redução da oferta e das matrículas por parte da Secretaria de Estado de Educação (Seeduc), somado ao fomento de políticas de correção de fluxo e de certificação, a exemplo do Exame Nacional para Certificação de Competências de Jovens e Adultos (ENCCEJA), cujo número de inscritos aumentou significativamente a partir de 2017 devido à massiva propaganda feita pelo governo federal (SERRA et al., 2018). Essa é uma percepção partilhada por um grupo de professores ao afirmar que "a destruição da escola presencial de EJA está mais perto que nunca. Precisaremos lutar muito contra isso. Querem nossos/as estudantes fora da escola" ${ }^{4}$ (Respondente 31 ). Contudo, os resultados da pesquisa indicam que o ensino remoto veio demonstrar a inconsistência da proposta de se ofertar a maior parte da carga horária da EJA por meio da EaD.

Com a pandemia da Covid-19, o parecer do Conselho Nacional de Educação (CNE) n. 5, publicado no fim de abril de 2020, autorizou a reorganização do Calendário Escolar e a possibilidade de contagem de atividades não presenciais para fins de cumprimento da carga horária mínima anual. Sobre a EJA, o parecer afirma que, enquanto perdurar a situação de emergência sanitária que impossibilite atividades escolares presenciais, as medidas recomendadas para o Ensino Fundamental e para o Ensino Médio, na modalidade EJA, devem considerar as suas singularidades na elaboração de metodologias e práticas pedagógicas, conforme os pareceres que instituem as Diretrizes Curriculares e as Diretrizes Operacionais para a EJA, levando em conta os objetivos de aprendizagem para o mundo do trabalho, a valorização dos saberes não escolares e as implicações das condições de vida e trabalho dos estudantes. Recomenda-se o diálogo com os estudantes na busca pelas melhores soluções, o incremento de apoio à infraestrutura das aulas e acesso à cultura e às artes, estimulando atividades e considerando-se ainda as especificidades do ensino noturno (BRASIL, 2020a).

Na sequência, em agosto de 2020, foi implementada a Lei n. 14.040, que estabeleceu normas educacionais excepcionais a serem adotadas durante o estado de calamidade pública (BRASIL, 2020b). De acordo com o texto da lei, poderão ser desenvolvidas atividades pedagógicas não presenciais no Ensino Fundamental e Médio, vinculadas aos conteúdos

\footnotetext{
4 Ao longo do trabalho, serão apresentados alguns fragmentos das narrativas dos sujeitos da pesquisa, doravante denominados respondentes, no intuito de fundamentar a análise aqui elaborada.
}

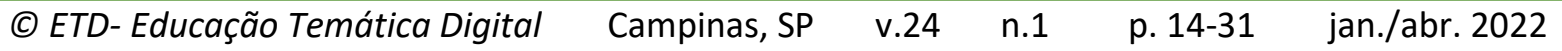


curriculares de cada etapa e modalidade, inclusive por meio do uso de tecnologias da informação e comunicação, cujo cômputo, para efeitos de integralização da carga horária mínima anual, obedecerá a critérios objetivos estabelecidos pelo CNE.

Seguindo essas orientações, as redes públicas de ensino do Rio de Janeiro determinaram a realização de atividades escolares em regime especial domiciliar-para todas as etapas da educação básica, incluindo a EJA. Com a finalidade de compreender o desenvolvimento das atividades pedagógicas para os estudantes da modalidade no ensino remoto emergencial, a pesquisa buscou identificar como tem sido o contato entre professores e alunos/alunas durante o período de afastamento social. Não obstante os resultados indiquem que $66 \%$ dos professores tenham estabelecido algum tipo de contato com os estudantes, $34 \%$ afirmam não manter contato com seus educandos.

Este é um dado preocupante por tratar-se de um público já invisibilizado nas políticas educacionais, o que pode incidir em uma "evasão em massa" no período pós-pandemia, como destacam alguns professores. Por essa razão, ainda que as orientações das redes públicas de ensino não vislumbrem formas específicas de atendimento pedagógico para os sujeitos da EJA, os professores consideram importante estabelecer algum contato com os educandos para saber sobre o bem-estar físico e emocional e como estão vivendo e se mantendo financeiramente no período da pandemia. Sobretudo, por compreenderem que a "EJA é resgate social e não apenas entrega de conteúdo" (Respondente 44). O relato de uma professora sintetiza o sentimento de muitas outras, quando diz:

\footnotetext{
Tenho sentido meus alunos muito desmotivados. Constantemente me perguntam quando vamos voltar. Eles reclamam do atendimento remoto. Então para amenizar e motivá-los a não desistirem, eu explico que nesse momento é o que podemos fazer, mas que em breve estaremos juntos. Costumo ligar para eles, pois desta forma fico mais próxima de cada um. O aluno da EJA precisa do atendimento presencial. Caso o atendimento remoto tenha que se estender por mais tempo, acredito que haverá muitas desistências, menos aprendizado e menos interesse por essa modalidade. (Respondente 63)
}

Quanto à forma de contato, $81,8 \%$ dos professores responderam que têm se utilizado do WhatsApp. Essa rede social tem sido utilizada como principal meio de comunicação devido à facilidade de suporte nos celulares e smartfones, pois abrange tanto mensagens escritas, quanto áudios, vídeos e mensagens não verbais, possibilitando a comunicação rápida entre professores e educandos e destes entre si. Não obstante a importância dessas atividades para a manutenção do vínculo dos alunos com a escola, ainda assim, "a parcela dos que participam é bem pequena" (Respondente 38). Ou seja, é "necessário para manter o vínculo afetivo, mas, infelizmente, não conseguimos alcançar todos os alunos", segundo uma professora (Respondente 40).

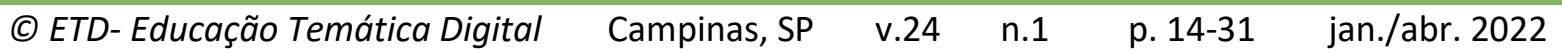


Decerto, o celular é uma ferramenta que auxilia na comunicação, mas não necessariamente na realização de tarefas pedagógicas. Assim,

[...] uma das críticas que se coloca quanto ao uso do celular para acesso à informação diz respeito ao tamanho da tela e impossibilidade de se efetuar leitura de documentos. Esse é um problema mais relacionado à compatibilidade dos arquivos de conteúdo ao caráter flexível de aumento de tamanho das fontes do que da limitação do aparelho, propriamente dito. Arquivos em formato PDF, por exemplo, não são flexíveis e não se adaptam ao tamanho da tela. (ARRUDA, 2020, p. 271)

Além dos estudantes, os professores também precisam dispor dos equipamentos tecnológicos necessários para o atendimento remoto, sendo ferramentas mais acessadas o celular/smartfone (92\%), o computador/notebook (89,3\%) e a banda larga de internet $(81,3 \%)$. Entretanto, os pesquisados informam que o investimento para aquisição das ferramentas necessárias para a comunicação com os estudantes advém do próprio professor, uma vez que na última década as redes públicas, com raras exceções, pouco investiram em tecnologias digitais como facilitadores nos processos de ensino e de aprendizagem e em formação docente para esta finalidade. A expectativa "seria de um ensino híbrido eficiente, se não houvesse o baixo interesse político de qualquer tentativa de informatizar as escolas ou de melhorar as condições dos alunos para um adequado contato e acesso remoto" (Respondente 21).

Assim, de forma imediata e por iniciativa própria, os professores relatam que tiveram que aprender a utilizar as ferramentas tecnológicas (ou aprimorar o seu uso) a fim de "dar conta dessa nova experiência profissional", não tendo sido fácil a adaptação ao novo formato pedagógico, que exigiu, ainda, a transposição das atividades presenciais para o ensino remoto sem a devida formação docente para tal mudança em pouco tempo. Por isso, alguns consideraram tratar-se de um processo "desgastante", "extremamente cansativo" e "sofrido", principalmente por perceberem que o ensino remoto emergencial não seria temporário, diante do agravamento da crise sanitária em decorrência da desarticulação das ações das esferas municipal, estadual e federal no combate à pandemia.

Todavia, a adaptação ao novo formato foi um processo muito mais sentido pelos estudantes, especialmente os da EJA, por algumas razões, entre elas, a dificuldade de acesso aos equipamentos. Dos professores pesquisados, 66 afirmaram (83,5\%) que seus alunos e alunas não dispunham dos recursos necessários ou adequados para o ensino remoto. Para 59 respondentes, a consequência imediatamente produzida é a de que menos de um terço de seus alunos estão conseguindo realizar as atividades. Para 15 professores a realidade é ainda mais grave, visto que apenas a metade consegue fazer as tarefas. Isso faz com que se aumente o "abismo social", expressão utilizada por $53 \%$ dos participantes da pesquisa. Este resultado vai ao encontro de demais estudos, que apontam que a pandemia

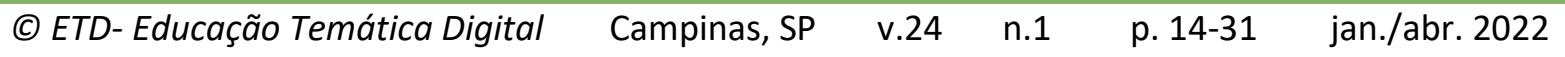


[...] evidencia ainda mais as diferenças sociais em que os recursos tecnológicos, cada vez mais avançados, não são para todos. Poucos têm acesso à internet de forma a utilizarem as TICS nos processos de ensino e de aprendizagem, tanto educando como os próprios professores. Faltam recursos materiais e letramento no uso das TIC. Assim, as atividades de aula se tornam listas de exercícios para casa, sem um auxílio docente que promova a aprendizagem, é um mero cumprimento de carga horária para conclusão do ano letivo. (PIRES et al., 2020, p. 17)

Esses dados se justapõem a outros. Em primeiro, o fato de $12,6 \%$ dos professores relatarem não conseguir enviar as atividades pedagógicas para seus alunos e alunas. Vale lembrar que, dada a condição socioeconômica, muitos estudantes da EJA são desprovidos de internet banda larga, computadores ou tablets, dando continuidade aos seus estudos por intermédio de aparelhos celulares e internet limitada a modestos pacotes de dados. Há, ainda, a mudança frequente do número do telefone devido ao uso de chips de baixo custo e de trocas constantes, gerando ruptura no contato entre professor e aluno. Outra questão que contribui para essa ruptura (definitiva ou parcial) é que muitos jovens e adultos trabalhadores se viram obrigados a procurar novas formas de garantir a reprodução da existência mediante perda de seus empregos e/ou ocupações. Dentre essas estratégias está o fenômeno da "uberização", que também inclui o sistema de entrega de alimentos e bebidas mediada por aplicativos e plataformas, o que os leva a ter de disponibilizar os aparelhos celulares para as atividades laborais. Ou seja, as necessidades emergenciais para a reprodução da existência não Ihes possibilitam uma escolha justa entre disponibilizar o celular para as atividades escolares ou o trabalho.

Na concepção dos pesquisados, "os governos desconsideram a realidade da maioria da população brasileira, onde metade não tem nem condições de se sustentar, o que comer" (Respondente 63). Daí a indignação ao fato de que "os governos não possam colocar uma internet nas comunidades mais carentes, ou chegar aos alunos por outros meios" (Respondente 47). Outros, advertem que o ensino deixa de ser uma prioridade para os seres humanos "quando sua própria existência está ameaçada, seja pela doença que nos assola, seja pela falta de emprego que causa a fome ou pela perda de entes queridos e amigos" (Respondente 35).

Não é só a falta de acesso às tecnologias digitais ou sua utilização, quando existem, que dificultam os educandos a realizarem as atividades propostas. Na concepção dos professores devem ser considerados, igualmente, os problemas com relação à leitura e à escrita convencionais; à alfabetização e letramento digital, as dificuldades financeiras e a desmotivação relacionada às questões da escola neste contexto pandêmico. Como se observa, não se trata de desafios restritos à escola, mas também implicados em questões sociais, produto e produtora da extrema desigualdade brasileira, que se acirra no contexto da pandemia da Covid-19 e que corroboram com os mecanismos de exclusão escolar.

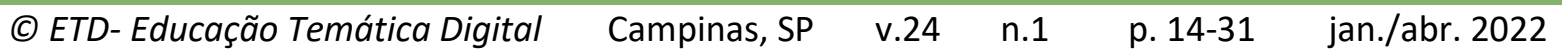


Em segundo, das atividades feitas pelos educandos apenas 20 professores consideraram que são realizadas satisfatoriamente. No caso, satisfatoriamente significa tentar realizar a tarefa e devolvê-la ao professor para que ele faça as considerações e/ou correções. Ademais, vale lembrar, que o dossiê produzido em 2020 pelo Fórum de EJA do estado do Rio de Janeiro, analisado por Nicodemos e Serra (2020), evidencia que 66,5\% dos professores pesquisados afirmaram que menos de $20 \%$ de seus estudantes acessavam a plataforma destinada à realização das tarefas. E 76,8\% disseram não haver regularidade na interação com seus educandos.

Sendo assim, procuramos verificar o tipo de atividade proposta pelos professores. Constatou-se que elas são organizadas em dois grupos: os que lidam diretamente com o conteúdo curricular e os que visam a manutenção do vínculo com a escola, pois entendem que o afrouxamento do deste pode incidir no total afastamento dos estudos e na evasão escolar. Dos respondentes, $17,5 \%$ disseram oferecer a seus estudantes atividades relacionadas diretamente ao conteúdo curricular e 33,3\% afirmaram propor apenas atividades que ocasionassem a manutenção de vínculo com os estudos e a escola. No entanto, a maioria $(49,1 \%)$ afirmou propor os dois tipos de atividades elencados.

Sanceverino et al. (2020) evidenciam, em seu estudo, que no ensino remoto a ausência de mediação docente é um desafio para os estudantes, uma vez que muitos não conseguem realizar a atividade proposta de forma autônoma. Chegamos a resultados semelhantes, tendo em vista a recorrência de respostas que ressaltam como é importante a mediação presencial para os estudantes da EJA. Embora o contato presencial seja um elemento de extrema importância para a construção e troca de conhecimentos em todas as etapas e modalidade da educação, na EJA a interação com o professor e os demais estudantes adquire um significado maior, por serem alguns educandos marcados por histórias de interdição, interrupção e/ou não sucesso escolar. Os professores asseveram que essa ausência impede/dificulta a aprendizagem, principalmente aos que se encontram em fase de alfabetização ou nos anos iniciais.

\begin{abstract}
Para a EJA, principalmente os alunos das séries inicia is, o ensino remoto é muito complicado. Eles têm necessidade da presença do professor, de proximidade, uma vez que a maioria deles mal consegue escrever o próprio nome. Eles não identificam as letras, não sabem ler, não têm autonomia. Isso os torna bastante dependentes do professor. Além disso, para eles é importante a convivência e a troca com os colegas. (Respondente 65)
\end{abstract}

As dificuldades encontradas por professor e estudantes para a realização de atividades pedagógicas não presenciais são decorrência de uma formação - inclusive a docente - que pouca atenção confere às práticas educativas mediadas por tecnologias, somada à falta de recursos materiais requeridos para o preparo de atividades mais significativas. Igualmente, por demandar dos estudantes determinadas competências e habilidades para a realização

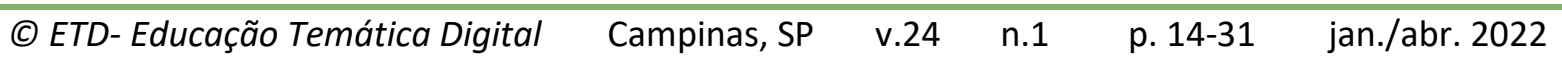


das atividades, como maior autonomia, capacidade de pesquisa, sistematização e organização. Contudo, essas dificuldades têm se constituído em motivador para a superação de algumas barreiras iniciais por parte dos professores, significando "importantes iniciativas no sentido de considerar a excepcionalidade do momento e desconstruir possíveis imobilismos que pudessem comprometer a importância da educação na vida das famílias" (ARRUDA, 2020, p. 264). Dos 79 pesquisados, 65 afirmam ter aprendido a usar as ferramentas ou recursos para as aulas remotas e consideram a superação das dificuldades iniciais um saldo positivo. Como expõe uma das participantes da pesquisa, "nós professores estávamos muito habituados a fazer sempre igual. Eu mesma adorei essa forma de ensinar" (Respondente 10).

Em relação aos estudantes, para a realização das atividades propostas, além da alfabetização digital e acesso aos equipamentos tecnológicos e à banda larga de internet, é preciso considerar os fatores de ordem econômica, social, condições de saúde, entre outros. Em diálogo com Lino (2020), as condições de saúde podem impedir/dificultar a exposição de adultos e idosos por longo tempo à frente da tela de um computador ou celular. Em termos econômico-sociais, as condições pouco adequadas de moradia de muitos estudantes não favorecem a existência de espaço-tempo apropriados para concentração e disciplina que o ensino remoto demanda. Segundo dados da Pnad de 2018, 6 milhões de brasileiros (3\%) não têm banheiro em casa; 31 milhões (15\%) não têm abastecimento de água próprio e cerca de 11 milhões de pessoas (6\% da população) vivem em ambientes com mais de três pessoas por cômodo (O TEMPO, 2020).

Não há um consenso entre os pesquisados quanto ao ensino remoto para a EJA em tempos de pandemia. A despeito das dificuldades para o acompanhamento e realização das atividades remotas, 33 professores são favoráveis a este formato em caráter emergencial alegando que "pior seria se os alunos esquecessem da escola e de tudo que aprenderam. A continuidade de atividades pela internet é muito boa para todos, pois continuam assimilando de diferentes maneiras os conteúdos de cada disciplina" (Respondente 19). Nessa mesma direção, um professor argumenta que:

[...] estamos em um momento que nunca vivenciamos, entretanto, não seria justo que nossos alunos ficassem prejudicados e comprometendo seus estudos mais uma vez em sua história vida. Por isso, sou a favor da educação remota no Brasil. Se cada um tomar para si a responsabilidade que temos diante da educação escolar, juntos venceremos os danos e prejuízos no processo de ensino aprendizagem. Claro que nada substitui a sala de aula, a troca entre docente e discente. (Respondente 08)

Devido às dificuldades de acesso dos estudantes às plataformas digitais e para a realização das atividades propostas, 46 professores $(58,2 \%)$ consideram que o ensino remoto é "sem produtividade", "incompleto e ineficiente" e que "não contribui para uma aprendizagem efetiva", já que "os alunos da EJA requerem assistência redobrada". Em

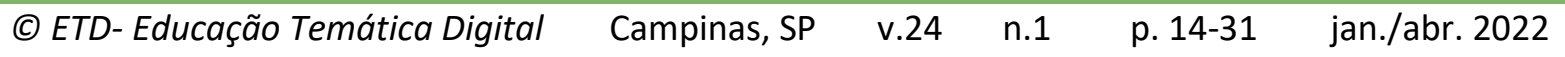


síntese, o argumento utilizado pelos que defendem essa posição é o de que "seria bom se todos ou pelo menos a maioria tivesse acesso ao ensino remoto", "uma vez que não alcança a quem mais precisa". Consideram tratar-se de "um fingimento do Estado [...]. Como uma escola pública pode produzir algo que sabe não atenderá nem metade dos seus alunos?" (Respondente 47). Tendo em vista que as condições não foram criadas para a inclusão de todos os estudantes, "o pior é ver muitas redes falarem que está sendo um sucesso" (Respondente 35). Na concepção dos professores, da forma como vem sendo desenvolvido o ensino remoto para a EJA, "é extremamente excludente e uma das piores ameaças à educação pública" (Respondente 33), pois pode vir a acelerar o projeto de desescolarização, ao se naturalizar o incentivo à mera certificação, destituída de conhecimentos significativos. E sentenciam: "é um engano achar que o pobre só quer diploma para trabalhar; muitos querem aprender. Se a questão é ter diploma, então que se distribua isso e o Estado assuma que não tem intenção de dar um ensino de qualidade para todos" (Respondente 45).

A percepção dos professores sobre o ensino remoto emergencial atrela-se, grosso modo, às especificidades de cada rede de ensino, escola e etapa da escolaridade em que atuam. As críticas mais contundentes são dos profissionais que atuam no segundo segmento do Ensino Fundamental e no Ensino Médio, pois, embora existam convergências no aspecto econômico-social entre os estudantes, os professores da alfabetização e dos anos iniciais, por exemplo, possuem desafios outros comparados aos demais segmentos. A educação mediada por tecnologias digitais tem sido um desafio maior para os estudantes da EJA em fase inicial da alfabetização. Afora as razões já elencadas neste texto, há o fato de ainda não terem pleno domínio da leitura e da escrita. E considerando que "qualquer atividade demanda uma mediação atenta e estimuladora, mas infelizmente não encontram isto em família" (Respondente 68), a manutenção do vínculo, a fim de apoiá-los psicologicamente "em face das suas inseguranças e dos sinais de depressão" (Respondente 64), e o estímulo a continuarem os estudos durante e pós-pandemia, são aspectos valorizados pelas professoras dos anos iniciais. $O$ aspecto geracional é igualmente considerado, uma vez que a alfabetização digital é maior entre os jovens do que entre adultos e idosos, que são a maioria dos estudantes da modalidade em fase de alfabetização.

Diante dessa divergência de posicionamento dos docentes sobre o ensino remoto emergencial para a EJA e a crítica de que "todos os alunos serão aprovados sem terem estudado" (Respondente 62), faz-se necessário refletir sobre o que os docentes pensam a respeito da avaliação e das aprendizagens dos estudantes construídas no período de pandemia. 


\section{SOBRE APRENDIZAGEM E AVALIAÇÃO NA EJA NO ENSINO REMOTO E PÓS- PANDEMIA: IMPRESSÕES DOS PROFESSORES}

Dentre as mudanças que o ensino remoto tem provocado na EJA, os professores atribuem que o distanciamento da escola e os desafios enfrentados para o cumprimento das atividades são as principais causas para o desestímulo e a desmotivação que observam em seus alunos e alunas. Apontam, inclusive, a desistência e a evasão de muitos estudantes, o que pode resultar no maior fechamento de turmas e escolas que oferecem a modalidade no período pós-pandemia, no estado do Rio de Janeiro. Desse modo,

\footnotetext{
No contexto da pandemia de Covid-19, os desafios a serem superados tornam-se ainda mais evidentes, visto que ainda não conseguimos promover políticas que possam garantir o total acesso, permanência e conclusão de estudos dos jovens e adultos dessa modalidade de ensino. (CUNHA JR. et al., 2020, p. 6)
}

A despeito das incertezas e de certo pessimismo quanto ao futuro da EJA no período pós-pandemia, os docentes consideram que o ensino remoto emergencial favoreceu a construção de novos conhecimentos e aprendizagens, entre elas, uma (maior) aproximação com as tecnologias digitais e "a reflexão sobre a importância de uma inclusão digital real do aluno da EJA, [devendo] reconhecer que é um sujeito de direitos e que precisa ser incluído no mundo digital" (Respondente 35). Nesse sentido, "o momento atual pode deixar um legado no que concerne à necessidade de inclusão digital" (Respondente 17), fazendo com "que o ensino na EJA pós-pandemia se torne efetivamente mais tecnológico" (Respondente 22). Para os professores do Ensino Médio, o ensino híbrido pode ser o anúncio de uma nova EJA, assinalando que podem "de alguma forma, mesmo que precária ou esporádica, fazer aulas diferentes utilizando os recursos tecnológicos em voga no período pandêmico" (Respondente 13). Para um período pós-pandemia, ressaltam que "as aulas precisam ser mais atrativas e o ensino remoto trouxe isso. Foi muito enriquecedor apresentar vídeos, ilustrações, e dispensar o aluno daquela 'aula de cópia' a qual estamos todos acostumados" (Respondente 10). Como se observa, defendem que as tecnologias passem a ser apropriadas como mais um instrumento de aprendizagem, "em especial nas áreas de conflito que muitas vezes ficam sem ter aula" (Respondente 38). Sem deixar de mencionar a desmotivação e o aprofundamento do abismo social por não se ter garantido a inclusão digital dos discentes, os professores sinalizam alguma positividade produzida no ensino remoto.

A consequência positiva é o fato de muitas vezes conseguir trabalhar determinado conteúdo de maneira diferente do que se tivesse em sala. Pois, para passar para os alunos um vídeo do YouTube em sala, por exemplo, seria necessário um Datashow, uma tomada funcionando, um som ou uma extensão elétrica, e muitas vezes a estrutura da escola não permite que essa aula aconteça. (Respondente 14)

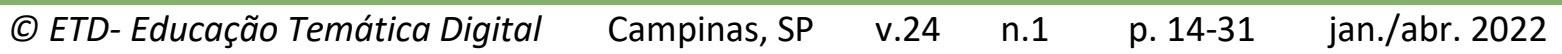


Porém, um outro grupo de professores chama a atenção de que a educação é um "campo muito resistente ao uso de tecnologias em seu cotidiano [...] Ainda vai demorar um tempo para o virtual se consolidar como um espaço de aprendizagem discente, pela falta de recursos físicos e de dados de internet" (Respondente 66). Os professores sinalizam que são muitos os desafios que deverão ser enfrentados pela EJA no período pós-pandemia e muitos desses desafios não dependerão exclusivamente dos professores e educandos, mas de políticas públicas que garantam "investimento em formação de professores, infraestrutura da escola e pesquisas científicas que norteiem a prática educacional na EJA" (PIRES et al., 2020, p. 17). Além da reestruturação em termos de calendário letivo, resolução sobre retenções, aprovações e certificação, bem como para a inclusão tecnológica e digital de alunos e professores, outro ponto salientado pelos professores após a retomada das aulas presenciais é o acolhimento dos educandos.

Um dos primeiros aspectos desse acolhimento diz respeito não só ao levantamento das atividades que foram possíveis com o ensino remoto, como também a proposta de avaliação das aprendizagens construídas, atravessadas pela questão de ordem emocional dos sujeitos envolvidos. A preocupação com o bem-estar físico e emocional de estudantes é o que mobiliza os professores a procurarem manter contato com os alunos e alunas por intermédio de redes sociais, buscando saber como estão, se conseguem manter os cuidados necessários para a não contaminação, se conseguem se manter financeiramente neste momento, especialmente aqueles que por diversas razões não conseguem realizar as atividades escolares. Sendo assim, as atividades desenvolvidas pelos professores - seja por meio das plataformas disponibilizadas pelas redes, seja o oferecimento de apostilas e exercícios físicos e/ou a proposta de jogos e vídeos enviados pelo WhatsApp que não demandam muitos esforços (no caso da fase da alfabetização) - têm servido para manter laços, cultivar relações, preservar a vida e proporcionar aprendizagens, sem o tradicionalismo das avaliações institucionais.

Ademais, a partir da concepção ampliada de EJA consolidada na Declaração de Hamburgo, em 1997, entende-se que todos nós, professores e alunos, estamos em processos permanentes de aprendizagens nas múltiplas relações as quais estabelecemos, nos variados espaços sociais e não somente na escola. Isso significa considerar que, do mesmo modo que - aprendizado acontece fora da escola, há conhecimentos que têm sido favorecidos/provocados pelo atual contexto de crise sanitária. Em relação aos professores, muitos têm aproveitado as brechas do tempo, entre cuidados com a casa e a família, para ler, estudar, assistir a filmes, a lives, participar de ações extensionistas promovidas pelas universidades, partilhando saberes e experiências. Dos conhecimentos construídos pelos estudantes, observa-se um maior cuidado consigo e com os outros, um aumento de solidariedade com todos, além de ter de aprender a conviver com o medo, com a morte, com o luto. Principalmente, diante do risco do contágio ao qual muitos estudantes da EJA estão

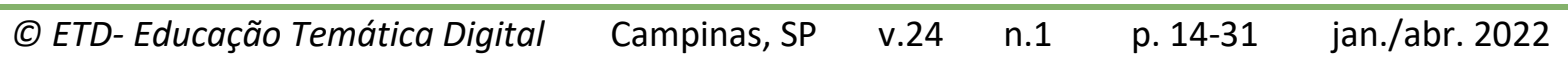


expostos, assim como os demais trabalhadores, por não terem a opção de permanecerem em casa.

A reflexão sobre as aprendizagens construídas no período de pandemia exige que os professores considerem a diversidade identitária dos estudantes matriculados na modalidade e, consequentemente, desenvolvam processos avaliativos e práticas pedagógicas que não sejam pautadas em instrumentos pedagógicos únicos, sem levar em consideração o processo de aprendizagem individual dos sujeitos e o modo como constroem conhecimentos e os articulam com as demandas do cotidiano. Processos avaliativos e práticas pedagógicas comprometidas com a inclusão e com a formação integral; que ao colocarem os educandos no centro do processo evidenciem

[...] o papel central do sujeito, de suas ações e de sua participação nas atividades de aprendizagem compreendida, então, como um processo ocorrendo ao longo do tempo, que pressupõe avanços e recuos, erros e acertos. Não há, como na tradição comportamentalista, a possibilidade de redução a avaliações dicotômicas, do tipo: aprendeu ou não aprendeu. Aprender envolve mudança, em especial, aquelas que caracterizam a emergência de novidades, em que aparecem condutas que indicam novas formas de ver, pensar, fazer ou falar. (SCHNEIDER, 2020, p. 78)

Por essa perspectiva, na EJA, aprender é muito mais do que assimilar conteúdos curriculares, realizar atividades e certificar-se. É também exercitar o "conteúdo" não muito priorizado pela escola no período anterior à pandemia, qual seja, o convívio com a diversidade humana, o autocuidado, a prevenção às doenças e a não exposição ao risco que incidem em mortes prematuras. A despeito de os professores reconhecerem a atipicidade do momento e as aprendizagens que são possíveis no contexto atual, expõem suas incertezas quanto ao futuro da EJA, por ser concebida pelas políticas e gestores públicos como uma educação menor, sobretudo em tempos de hegemonia neoliberal, de ataques aos direitos e de redução de investimentos públicos na área social. O receio é de que, no contexto pós-pandemia, o ensino híbrido, defendido por um grupo de professores, possa vir a acelerar o processo de desescolarização da modalidade, gerando o que denominam de "consequências perigosas".

\footnotetext{
Muitos tentarão dizer que foi um sucesso e que deve ser mantido após a pandemia. Balela de quem quer oferecer uma educação mínima para o povo enquanto os seus filhos estudam em escolas com tempo integral. Para a elite tudo, para a população mais carente, qualquer coisa. (Respondente 45)
}

Os argumentos dos professores - em alguns momentos polarizados - expõem que mais uma vez a modalidade tem sido colocada "em um local de fronteira, de disputa entre concepções de currículo e políticas educacionais" (NICODEMOS e SERRA, 2020, p. 888). Essa correlação de forças pode vir a suscitar a renovação da EJA, apesar do sofrimento ocasionado pela pandemia e do desmonte das políticas públicas direcionadas à modalidade pelo governo federal. Principalmente por reconhecer que a EJA é constituída por um processo histórico permanente de luta. É a força da mobilização de muitos sujeitos coletivos que afirmará, mais

$\begin{array}{llllll}\text { (C) ETD-Educação Temática Digital } & \text { Campinas, SP } & \text { v.24 } & \text { n.1 } & \text { p.14-31 } & \text { jan./abr. } 2022\end{array}$


uma vez, o direito de todos à educação, conforme previsto na Constituição. De uma educação pública, conectada com os avanços tecnológicos e com a era digital-molecular.

\section{CONSIDERAÇÕES FINAIS}

As reflexões aqui tecidas objetivaram identificar o modo como os professores da EJA têm vivenciado o ensino remoto emergencial ocasionado pela pandemia da Covid-19. Ao ouvir os sujeitos implicados no processo de ensino e de aprendizagem, a presente pesquisa buscou compreender de forma ampla, mas sem buscar generalidades, as mediações que têm dificultado/possibilitado o direito à aprendizagem dos estudantes jovens, adultos e idosos que se encontram nos Ensinos Fundamental e Médio. Os resultados revelam que as singularidades da EJA não devem ser pensadas apenas em relação às outras modalidades, mas também internamente, tanto na perspectiva da diversidade dos sujeitos atendidos quanto no grau de institucionalidade que a EJA adquire nas distintas redes de ensino. Essas demarcações possibilitam-nos perceber as diferenças de concepções acerca das finalidades e o papel político-social que os professores conferem à modalidade.

Isso se explicita quando os professores expõem sua opinião sobre as mudanças que o ensino remoto emergencial tem provocado na EJA, as aprendizagens construídas por eles e pelos educandos no atual contexto, bem como suas expectativas para o período póspandemia. Quanto a essas questões, o descenso - salutar! - exposto nos argumentos dos sujeitos da pesquisa mostra que o seu lugar de fala é permeado pela faixa etária, o tempo de exercício profissional na modalidade, a rede de ensino e a etapa da escolaridade em que atuam. Significa com isso salientar que o ensino remoto na fase da alfabetização possui especificidades e desafios diferentes daqueles do Ensino Médio. E são por meio desses desafios e experiências distintos que os professores refletem a modalidade, a sua prática pedagógica e as (não) respostas dos alunos e alunas.

Um dos pontos que apresenta relativo consenso entre os pesquisados é a baixa adesão dos estudantes às plataformas digitais e às atividades remotas, ocasionada pelo não acesso aos equipamentos tecnológicos, à banda larga de internet e/ou à baixa alfabetização digital, mas também por fatores de ordem econômica (dada a precarização das condições de existência), social (por conta de moradia inadequada para o ensino remoto), pedagógico (por demandar a mediação presencial), psicológica e emocional (ocasionada pelo distanciamento social, pelas perdas em diversas esferas da vida e pelas incertezas que impossibilitam, mais do que anteriormente, a fazerem planos a longo prazo).

As críticas que os professores tecem ao ensino remoto para a EJA circunscreve-se à forma como ele tem sido desenvolvido. A ausência de políticas que garantam o acesso dos estudantes aos equipamentos tecnológicos, à internet e às condições adequadas de

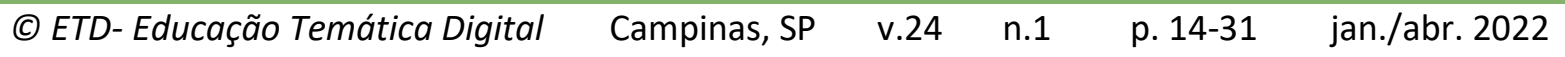


sobrevivência contribui para acirrar ainda mais as desigualdades sociais. Por outro lado, o resultado da pesquisa aponta para um modelo de escola que precisa se reinventar; é essa a aposta que alguns professores fazem no ensino híbrido após o retorno das atividades presenciais. Ressaltam, para isso, a necessidade de se promover a verdadeira inclusão digital dos estudantes da EJA em todas as fases da escolaridade, o que só pode acontecer com um governo comprometido com a educação e com a efetivação dos direitos humanos, implementando políticas públicas que venham possibilitar a educação mediada por tecnologia digitais, por compreendê-las como um recurso a mais no processo de ensino e de aprendizagem. As dificuldades sinalizadas pelos professores para adaptação ao novo fazer pedagógico evidenciam que a formação docente tem de fazer parte desse investimento. A questão é: diante da invisibilidade da EJA na agenda do atual governo federal, professores, pesquisadores e estudantes da modalidade estarão dispostos a se organizarem a fim de enfrentar coletivamente as adversidades que se colocam para a renovação da EJA?

\section{REFERÊNCIAS}

ARRUDA, Eucidio Pimenta. Educação remota emergencial: elementos para políticas públicas na educação brasileira em tempos de Covid-19. EmRede - Revista de Educação a

Distância, v. 7, n. 1, p. 257-275, 2020. Disponível em:

https://www.aunirede.org.br/revista/index.php/emrede/article/view/621 Acesso em: 17 abr. 2021.

BARBOSA, Carlos Soares; SILVA, Jaqueline Luzia da. Reflexões sobre a destituição do direito à educação de jovens, adultos e idosos no Brasil no tempo presente. Revista Humanidades e Inovação, v. 7, n. 19, p. 139-153, 2020.

BRASIL. Ministério da Educação. Lei de Diretrizes e Bases da Educação Nacional n. 9394/96. Brasília, DF: Senado Federal, 1996.

BRASIL. Ministério da Educação. Conselho Nacional de Educação. Parecer CNE/CEB n. 11/2000. Brasília: CNE: MEC, 2000.

BRASIL. Ministério da Educação. Conselho Nacional de Educação. Resolução n. 3, de 15 de junho de 2010. Brasília: CNE: MEC, 2010.

BRASIL. Ministério da Educação. Decreto n. 9.057 de 25 de maio de 2017. Brasília: MEC, 2017.

BRASIL. Ministério da Educação. Conselho Nacional de Educação. Parecer CNE n. 05/2020. Brasília: CNE MEC, 2020a.

BRASIL. Subchefia para assuntos jurídicos. Lei n. 14.040, de 18 de agosto de 2020. Brasília: CNE MEC, 2020b.

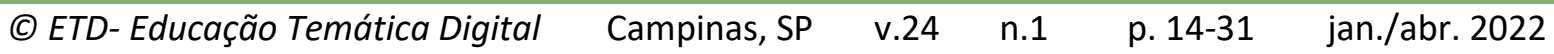


CUNHA JÚNIOR, Adenilson Souza; MATEUS, Kergileda Ambrósio de Oliveira; LIMA, Marileide Moutinho Pomponet; MENEZES, Mônica Clementino de; COSTA, Solange Balisa. Educação de Jovens E Adultos (EJA) no Contexto da Pandemia de Covid-19: Cenários e Dilemas em Municípios Baianos. Revista Encantar - Educação, Cultura e Sociedade, Bom Jesus da Lapa, v. 2, p. 01-22, jan./dez. 2020. Disponível em: http://dx.doi.org/10.46375/encantar.v2.0042 Acesso em: 19 abr. 2021.

LINO, Lucília Augusta. As consequências e contradições da adoção do ensino remoto na EJA no pós-pandemia. Fórum de Educação de Jovens e Adultos, vídeo, 2020. Disponível em: https://www.youtube.com/watch?v=FzIEbFcgn9o Acesso em: 13 mai. 2021.

NICODEMOS, Alessandra; SERRA, Enio. Educação de Jovens e Adultos em contexto pandêmico: entre o remoto e a invisibilidade nas políticas curriculares. Currículo sem Fronteiras, v. 20, n. 3, p. 871-892, set./dez. 2020. Disponível em: https://www.curriculosemfronteiras.org/vol20iss3articles/nicodemos-serra.pdf Acesso em: 15 abr. 2021.

O TEMPO. Mais de 11 milhões moram em casas superlotadas, 08 de março de 2020. Disponível em: https://www.otempo.com.br/brasil/mais-de-11-milhoes-no-brasil-moramem-casas-superlotadas-1.2317766 Acesso em: 04 set. 2020.

PIRES, Luciene Lima de Assis; DOS REIS LIMA, Walkíria; DE SOUZA, Paulo Henrique. A Educação de Jovens e adultos: o educando e o contexto da pandemia. Itinerarius Reflectionis, v. 16, n. 1, p. 01-20, 2020. Disponível em: https://www.revistas.ufg.br/rir/article/view/65616 Acesso em: 18 abr. 2021.

SANCEVERINO, Adriana; BERGER, Daniel Godinho; LAFFIN, Maria Hermínia Lage Fernandes; ATHAYDE, Maria Cristina de Oliveira; GONÇALVES, Rita de Cássia Pacheco. A EJA em Santa Catarina no contexto da pandemia da Covid -19. Fórum de Educação de Jovens e Adultos de Santa Catarina, Santa Catarina, 2020.

SCHNEIDER, Sonia Maria. Aprendizagem na educação de pessoas jovens, adultas e idosas. In: FERNANDES, Andrea da Paixão; LOPES, Paula Cid (Org.). O cotidiano escolar de crianças, jovens e adultos em roda de conversas. Rio de Janeiro: Eduerj, 2020.

SERRA, Enio; VENTURA, Jaqueline; ALVARENGA, Márcia; REGUERA, Emilio. Interrogando o direito à educação: oferta e demanda por Educação de Jovens e Adultos no estado do Rio de Janeiro. Crítica Educativa, v. 3, n. 3, p. 25-41, 2018. Disponível em:

https://www.criticaeducativa.ufscar.br/index.php/criticaeducativa/article/view/243 Acesso em: 3 nov. 2021.

Revisão gramatical realizada por: Helena Cristina Gomes.

E-mail: hcristinagomes@gmail.com 